\title{
Evaluation of serum biomarkers and efficacy of MTX in women with ectopic pregnancy
}

\author{
HAIYAN LI, YING LIU, SHUBIN WEN, HANBING JIA and YUANJIE DU \\ The Second Hospital of Hebei Medical University, Shijiazhuang, Hebei 050000, P.R. China
}

Received December 8, 2018; Accepted May 10, 2019

DOI: $10.3892 / \mathrm{mmr} .2019 .10533$

\begin{abstract}
Ectopic pregnancy occurs when a fertilized ovum attaches outside the uterus. As a complication in approximately $1-2 \%$ of all pregnancies, ectopic pregnancies may cause catastrophic hemorrhage as a result of invading maternal blood vessels. Therefore, early diagnosis and timely treatment are crucial for women with ectopic pregnancy. In this study, we aimed to identify and determine the efficacy of serum biomarkers for the prompt diagnosis of ectopic pregnancy. For this purpose, the serum concentrations of progesterone, $\beta$ human chorionic gonadotropin $(\beta-\mathrm{hCG})$ and cancer antigen-125 (CA125) were detected by solid-phase, competitive binding chemiluminescent enzyme immunoassays. Flow cytometry was used to analyze the percentage of $\mathrm{CD}^{+} \mathrm{T}$ cells in women with ectopic pregnancy. Pathological analysis of tubal and villus tissues was performed by hematoxylin and eosin (H\&E) staining. After receiving an injection of methotrexate (MTX), patients were examined by transvaginal ultrasound to detect the size of the echogenic mass. The results revealed that the serum levels of progesterone, $\beta$-HCG and CA125 were significantly decreased in women with ectopic pregnancy, whereas the percentage of $\mathrm{CD} 3^{+} \mathrm{T}$ cells was increased in women with ectopic pregnancy. Histopathological examination revealed blood clots with small tissue fragments of a tubal-type epithelium and incomplete pile structures. Five days after the MTX injection, an echogenic mass was found with a size of $1.7 \times 1.2 \times 1.6 \mathrm{~cm}$ that contained a gestational sac-like structure and a yolk sac. On the whole, the findings of this study indicate the at the joint detection of progesterone, $\beta$-HCG, CA125 serum levels and the $\mathrm{CD}^{+} \mathrm{T}$ cell percentage could be applied as a reliable indicator for the early diagnosis
\end{abstract}

Correspondence to: Dr Yuanjie Du, The Second Hospital of Hebei Medical University, 215 Heping West Road, Shijiazhuang, Hebei 050000, P.R. China

E-mail: duyuanjiekiddsai@163.com

Abbreviations: $\beta$-hCG, $\beta$ human chorionic gonadotropin; CA-125, cancer antigen-125; MTX, methotrexate

Key words: ectopic pregnancy, progesterone, $\beta$ human chorionic gonadotropin, cancer antigen-125, methotrexate of ectopic pregnancy. MTX administration was determined to be an efficacious approach for the treatment of ectopic pregnancy.

\section{Introduction}

Ectopic pregnancy is a complication of pregnancy in which the gestational sac attaches outside the uterus (1). The reported rate of ectopic pregnancy is approximately $2 \%$ and has significantly increased over the past few decades (2-4). Tubal pregnancy is the most common form of ectopic pregnancy. Vaginal bleeding and abdominal pain are classic signs and symptoms of ectopic pregnancy, which may cause maternal morbidity and accidental mortality in early pregnancy (5-7). Although the spontaneous shedding of ectopic pregnancy may occur, patients are still at risk of catastrophic hemorrhage and tubal rupture (8). In addition, women with ectopic pregnancy have a higher risk for another ectopic pregnancy or subfertility (9). Although the frequency of this severe situation is relatively high, the early detection of ectopic pregnancy remains challenging (10). More than half of all women with ectopic pregnancy who present at the emergency department are not identified at the initial medical assessment $(5,11)$. Thus, during the early gestational period, obtaining a correct diagnosis is rather difficult.

Pregnancy is diagnosed by measuring the serum or urine concentration of $\beta$ human chorionic gonadotropin ( $\beta$-hCG) in the emergency department (12). As early as 1 week following conception, $\beta$-hCG can be detected in the blood and urine (13). However, the detection of the $\beta$-hCG concentration alone cannot identify the exact location of the gestational sac (14). It has been observed that the serum concentration of progesterone may be a potentially useful co-factor for the measurement of serum $\beta$-hCG levels since progesterone levels are stable and independent of gestational age in the first 3 months (15). Cancer antigen-125 (CA-125) is generally considered a biomarker of ovarian cancer (16). However, in benign conditions, such as endometriosis, where inflammation or peritoneal irritation are present, CA-125 levels are also increased (17). The serum CA-125 level has been reported to be increased in women with viable intrauterine pregnancies (18). In addition, women with ectopic pregnancies have a wide range of CA-125 concentrations, although overall, the concentrations are lower compared to those in women with intrauterine pregnancies (18). 
As opposed to medical surgery, the use of methotrexate (MTX), an anti-folate antagonist, has been progressively administered for the treatment of ectopic pregnancy (19). Methotrexate acts as a competitive inhibitor of folinic acid and blocks DNA and RNA synthesis by inhibiting folinic acid incorporation into thymidine and purines (20). Notably, trophoblast tissues, which possess the ability to rapidly divide, are exceedingly sensitive to MTX treatment (21).

In this study, we investigated the early diagnosis and treatment of patients with ectopic pregnancy. The pathological changes in patients with ectopic pregnancy were analyzed by detecting abnormal indexes, such as those of progesterone, $\beta$-hCG and CA-125 along with the changes in immune cells. To explore the efficacy of MTX, we treated patients with MTX to terminate embryonic development and detected the gestational size by transvaginal ultrasound. The early diagnosis of ectopic pregnancy and the selection of appropriate treatment methods are crucial for reducing the mortality of pregnant women and for improving future pregnancy rates of patients with ectopic pregnancy.

\section{Materials and methods}

Patients. From September, 2014 to April, 2017, 100 women with ectopic pregnancy and 100 women with a normal, early pregnancy were recruited in this study. Women in both groups were in the early stage of gestation, and no significant differences were observed as regards the gestational age. The gestational age was determined by the first day of the last menstrual period. Of the 100 patients with ectopic pregnancy, 52 patients underwent surgery and 48 patients received medication. Patients with ectopic pregnancy who underwent surgery were examined for pathological damage of the fallopian tubes and villus tissue during the surgery. Another 48 patients received medication and were monitored by vaginal ultrasound. None of the women with ectopic pregnancy who were involved in this study had any abnormalities such as those in the ovary and cornea, or a caesarean section scar. Written consents were obtained from all the participants. The Ethics Committee of The Second Hospital of Hebei Medical University approved all the experiments in this study.

Chemiluminescent enzyme immunoassays. The serum levels of progesterone, $\beta$-HCG and CA125 were examined by solid-phase, competitive binding chemiluminescent enzyme immunoassays (Siemens Immulite 2000) as previously described (22).

Flow cytometry. Peripheral blood was collected from the patients, and peripheral blood mononuclear cells (PBMCs) were isolated using Ficoll reagent (Sigma-Aldrich; Merck $\mathrm{KGaA}$ ). PBMCs were carefully washed in PBS and were subsequently stained with a fixable viability dye. After washing, the cells were labeled with an anti-CD3 antibody conjugated to a fluorescent dye (1:1,000; cat. no. 48-0032-82; eBioscience; Thermo Fisher Scientific, Inc.) for $30 \mathrm{~min}$ at $4^{\circ} \mathrm{C}$. A BD FACSVerse flow cytometer was used to quantify the labeled cells, and FlowJo Software (BD Biosciences) was used to analyze the collected data.
Histopathological examination. For patients with ectopic pregnancy undergoing salpingectomy, we collected oviduct tissue for hematoxylin and eosin (H\&E; Sigma-Aldrich; Merck $\mathrm{KGaA}$ ) staining during surgery. H\&E staining was performed according to standard protocols and was used for the pathological diagnosis of ectopic pregnancy (original magnification, $\mathrm{x} 100)(23)$.

Statistical analysis. All data are presented as the means \pm SD. Differences between samples were analyzed using a two-tailed Student's t-test. $P<0.05$ was considered to indicate a statistically significant difference.

\section{Results}

Serum levels of progesterone, $\beta-H C G$ and CA125 are significantly decreased in women with ectopic pregnancy. For this study, we recruited 100 women with ectopic pregnancy along with 100 women with normal early pregnancy as controls from September, 2014 through April, 2017. Women in both groups were in the early stage of gestation, and no significant differences were observed as regards the gestational age, which was determined by the first day of the last menstrual period. The serum concentrations of progesterone, $\beta$-hCG and CA125 were assessed using solid-phase, competitive binding chemiluminescent enzyme immunoassays. As shown in Fig. 1A and C, women with ectopic pregnancies expressed lower progesterone and CA125 levels than those with normal early pregnancies $(\mathrm{P}<0.01)$. In addition, the serum $\beta$-hCG levels were significantly decreased in women with ectopic pregnancy $(\mathrm{P}<0.001)$ compared with women with normal early pregnancy, as depicted in Fig. 1B.

The percentage of $\mathrm{CD}^{+} \mathrm{T}$ cells is increased in women with ectopic pregnancy. The expression of $\mathrm{CD} 3$ throughout all stages of $\mathrm{T}$ cell development indicates that it is a useful marker for T cells. Thus, in this study, we performed flow cytometry to isolate $\mathrm{CD}^{+} \mathrm{T}$ cells from the peripheral blood of women with ectopic pregnancy and women with a normal early pregnancy (Fig. 2A). As shown in Fig. 1B, the percentage of $\mathrm{CD}^{+} \mathrm{T}$ cells was significantly higher in women with ectopic pregnancy than in women with normal early pregnancy $(\mathrm{P}<0.01)$.

Histopathological examination of ectopic pregnancy. The degree of pathological damage to the fallopian tubes and villi in patients with ectopic pregnancy was determined by $\mathrm{H} \& \mathrm{E}$ staining. As shown in Fig. 3A, blood clots were observed around the tubal mass, and epithelial tissue fragments had been shed from the fallopian tube. In addition, the structure of the fallopian tube was not complete in women with ectopic pregnancy (Fig. 3B). These data suggested that the increase in peripheral $\mathrm{CD}^{+} \mathrm{T}$ cells in patients with ectopic pregnancy promoted the occurrence of inflammation, which may cause pathological damage to fallopian tubes and villi.

Transvaginal ultrasound images after MTX injection. To terminate the abnormal pregnancy, the patients were subjected to a single intramuscular injection of MTX $\left(50 \mathrm{mg} / \mathrm{m}^{2}\right)$. Transvaginal ultrasound revealed that the size of the echogenic mass was $1.7 \times 1.2 \times 1.6 \mathrm{~cm}$ and included an inner gestational 

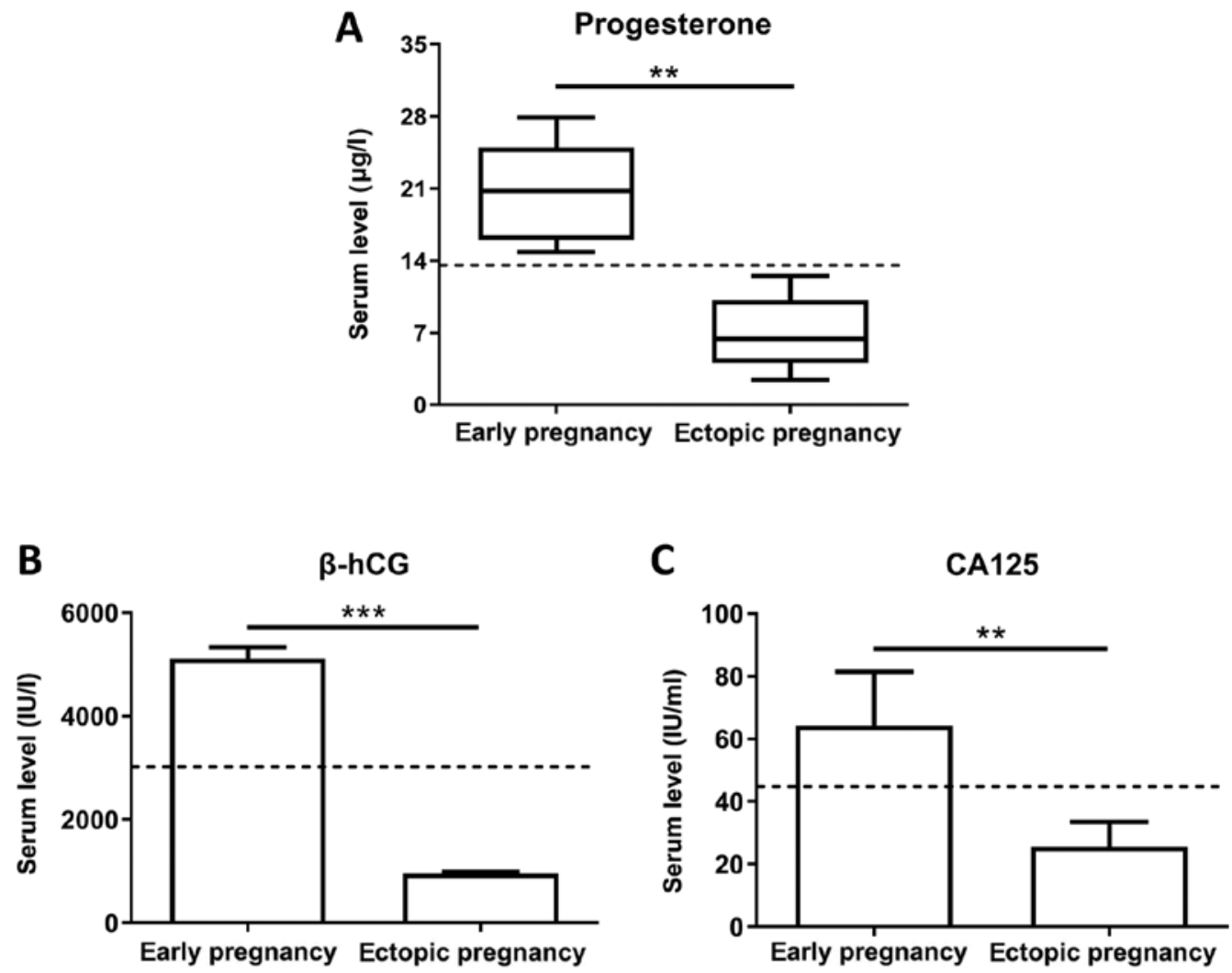

Figure 1. Serum levels of progesterone, $\beta$-HCG and CA125 are reduced in ectopic pregnancy. (A-C) Serum levels of progesterone, $\beta$-HCG and CA125 in women in early pregnancy and those with ectopic pregnancy were evaluated. The dashed bars indicate the cut-off values in our criteria (Progesterone $<13.65$; $\beta$-hCG $<3036 ; \mathrm{CA} 125<45.00)$. Data are shown as the means $\pm \mathrm{SD} ;{ }^{* *} \mathrm{P}<0.01$ and $^{* * * *} \mathrm{P}<0.001 . \beta-\mathrm{HCG}, \beta$ human chorionic gonadotropin; $\mathrm{CA} 125$, cancer antigen-125.

A
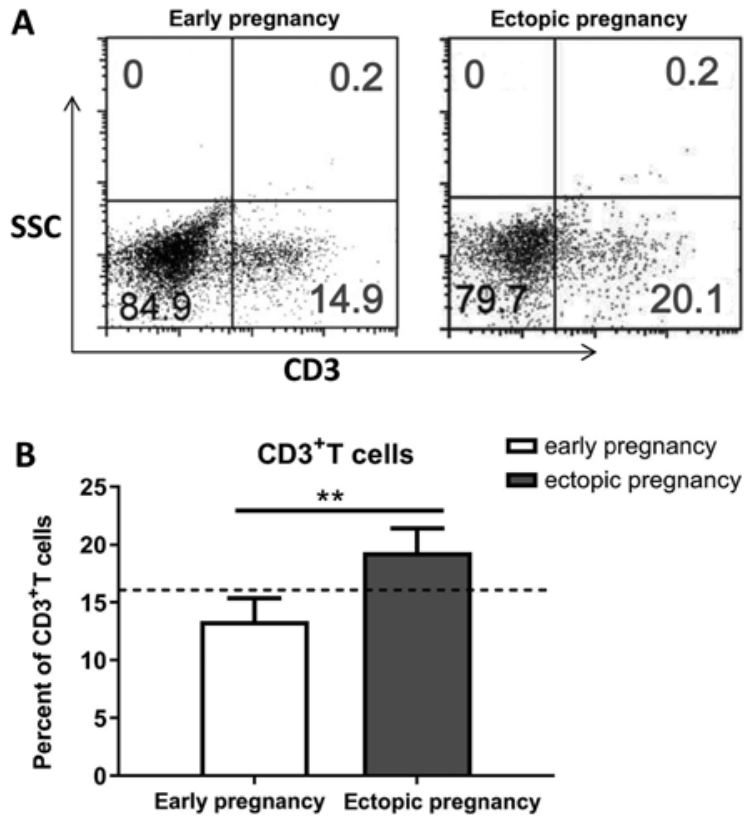

Figure 2. Percentage of $\mathrm{CD}^{+} \mathrm{T}$ cells is enhanced in women with ectopic pregnancy. (A and $\mathrm{B}$ ) Percentage of $\mathrm{CD}^{+} \mathrm{T}$ cells in women in early pregnancy and women with ectopic pregnancy was analyzed by flow cytometry. The dashed bars indicate the cut-off values in our criteria $\left(\mathrm{CD}^{+} \mathrm{T}\right.$ percentage $>16.33$ ). Data are shown as the means $\pm \mathrm{SD} ;{ }^{* *} \mathrm{P}<0.01$.

sac-like structure and a 0.2-cm-sized yolk sac (Fig. 4). These data further confirmed that MTX administration was an efficacious approach for the treatment of patients with ectopic pregnancy.

\section{Discussion}

Ectopic pregnancy is a serious obstetrical disease that can be fatal in the first trimester of pregnancy (24). The most common complication is hypovolemic shock, which is caused by tubal rupture and subsequent internal bleeding (25). Death from tubal rupture still ranks as the leading cause of mortality among women in their first trimester of pregnancy (26). Therefore, early diagnosis and timely treatment are essential for women with ectopic pregnancy $(27,28)$. Previous studies have revealed that blood-based biomarkers can be used to identify an ectopic pregnancy when ultrasound cannot determine the exact location of the embryo, which would contribute to an early diagnosis (29). In this study, we explored several biomarkers that can be used to diagnose ectopic pregnancy; these biomarkers may be crucial for early definitive treatment and management.

Pregnancy is initially diagnosed based on the serum or urine $\beta$-hCG concentration (30). However, the measured $\beta$-hCG concentration alone cannot identify the exact location of the gestational sac $(31,32)$. Although the $\beta$-hCG concentration in women with ectopic pregnancy tends to be lower compared to that in women with an intrauterine pregnancy, a considerable overlap has been found (33). Thus, a low level of serum $\beta$-hCG $(<1,000 \mathrm{IU} / \mathrm{l})$ is commonly associated with a higher probability of ectopic pregnancy, whereas a single very 

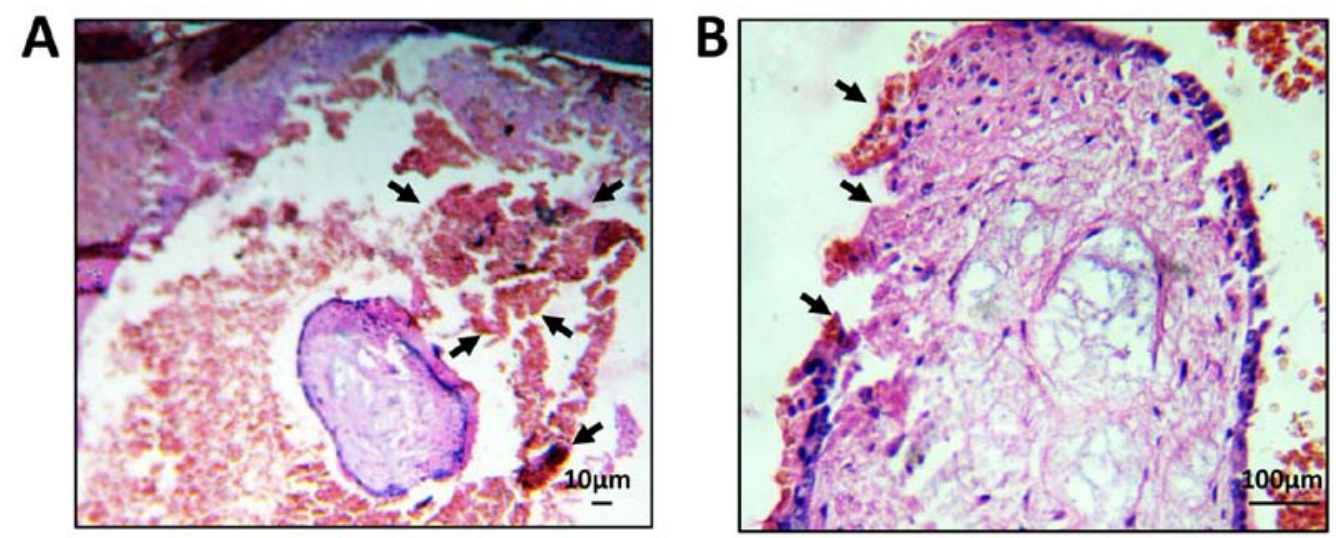

Figure 3. Pathological analysis of women with ectopic pregnancy. (A and B) Pathological analysis of fallopian tubes and villus tissue in ectopic pregnancy was performed by H\&E staining. Magnification: (A) x100 and (B) x400.
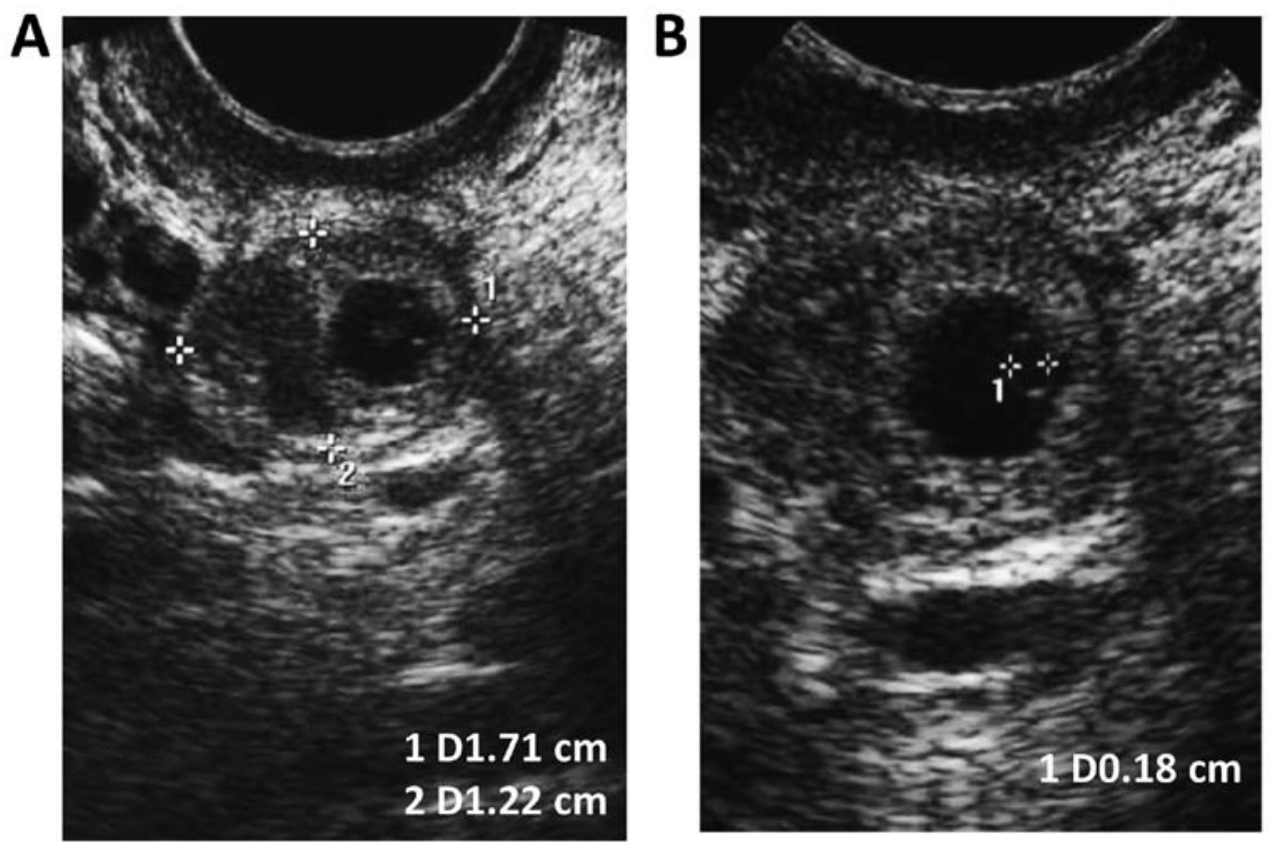

Figure 4. Transvaginal ultrasound images after MTX injection. (A) Transvaginal ultrasound was performed 5 days after MTX injection; an echogenic mass was found in the ovary. (B) An inner gestational sac-like structure and a $0.2-\mathrm{cm}$-sized yolk sac. MTX, methotrexate.

low serum $\beta$-hCG level $(<100 \mathrm{IU} / \mathrm{l})$ cannot predict a benign clinical condition (34). Although a single very low level $(<100 \mathrm{IU} / \mathrm{l})$ may not indicate an adverse outcome, in a review of 716 confirmed cases of ectopic pregnancy, 208 of those with a very low level experienced tubal rupture according to laparoscopy (35). In addition, the risk of tubal rupture does not seem to be associated with the $\beta$-hCG level (36). Another study found that the serum $\beta$-hCG levels ranged from 10 to $189,720 \mathrm{IU} / 1$ in 38 women with tubal rupture (37). Thus, the concentration of serum $\beta$-hCG alone cannot eliminate the possibility of ectopic pregnancy or predict the risk of fallopian tube rupture.

Progesterone has been long considered an effective marker that distinguishes a normal early pregnancy (higher levels) from an ectopic pregnancy or miscarriage (lower levels in both) (38). Since the serum concentrations of progesterone are stable and unrelated to gestational age in the first trimester, progesterone has been considered an effective adjunct to serum $\beta$-hCG in early pregnancy (39). Actually, any possible method (if any) used to diagnose ectopic pregnancy may be used in conjunction with other biomarkers (40).

CA-125 is a typical biomarker indicative of ovarian cancer (41). Its levels are also frequently elevated in non-malignant conditions, including pelvic inflammatory disease, leiomyoma, endometriosis and pregnancy (42). In one study, the CA-125 levels were found to be increased in the first trimester of pregnancy and immediately postpartum (43). It has also been reported that CA-125 can be used as an adjunct to $\beta$-hCG to distinguish between fallopian tube abortion and viable ectopic pregnancy (44). Others have found that women with normal early pregnancy, hydatidiform mole and spontaneous abortion expressed high levels of serum CA-125; however, lower levels were observed in women with tubal pregnancy, particularly in the absence of uterine bleeding (45). The peak CA-125 level is typically observed in the maternal serum in early pregnancy and immediately postpartum, 
and this transient increase in CA-125 may be caused by the destruction of decidual tissues (46). Brumsted et al (17), reported that CA-125 levels were relatively lower in women with abnormal pregnancies compared with those with normal intrauterine pregnancies and that this led to a greater risk of bleeding. Thus, CA-125 may be clinically relevant in early pregnancy surveillance.

MTX has been used as a medical alternative to surgery for women with ectopic pregnancy since the 1990s (47). Previous studies demonstrated that MTX had a success rate of approximately $94 \%$ when administered to the appropriate patients (48). The success rate of MTX treatment for ectopic pregnancy is largely dependent on the $\beta$-hCG concentration (49). A meta-analysis revealed that MTX treatment decreased the serum $\beta$-hCG level, which indicates that increasing levels of $\beta$-hCG are significantly associated with treatment failure (50). Furthermore, MTX is more effective when administered to small ectopic pregnancies compared with large ectopic pregnancies (51).

Multiple-dose MTX treatment has an overall success rate of $93 \%$, whereas single-dose MTX has a lower rate of $88 \%$ (52). However, multiple-dose therapy is more expensive, has a higher rate of side effects, and requires more intensive and continuous monitoring and rescue with folinic acid (53). Moreover, single-dose therapy is actually efficacious in most cases of ectopic pregnancy. However, multiple-dose MTX treatment should be considered in cases of relative contraindications, including the presence of fetal cardiac activity and high serum $\beta$-hCG concentration ( $\geq 5,000 \mathrm{IU} / 1)$ (54). A recent systematic review and meta-analysis revealed that the incidence of side effects in the two-dose regimen was similar to that of the single-dose regimen (54). However, side-effects are more common in multiple-dose regimens (54). This meta-analysis revealed that the incidence of side-effects due to the multi-dose regimen was significantly higher than that due to the single-dose regimen; both regimens had a similar success rate (54). Therefore, the dual-dose regimen is an effective and safe alternative to the single-dose regimen (54). Recently, new research has been conducted to try to establish a safer solution with similar efficacy and minimal side effects. To this end, some researchers have developed clinical trials of combining MTX with other drugs (55).

Notably, patients treated with MTX should be paid close attention, and serum $\beta$-hCG levels should be examined once a week. Three or four days after MTX administration, the serum $\beta$-hCG level should be decreased, and thus an increased level is abnormal (56). A second dose of MTX should be administered if the serum $\beta$-hCG level has not decreased by at least twenty-five percent one week after the first MTX treatment (57). Overall, a second dose is required in 15 to $20 \%$ of patients, and only $1 \%$ of patients require more than two doses (58). MTX treatment may cause hematoma formation, which may result in abdominal pain from tubal distention or abortion in patients $(59,60)$. However, severe abdominal pain may be necessary for fallopian tube rupture that is imminent or that has already begun. A rupture can occur even when the $\beta$-hCG levels continue to decrease after MTX treatment (55). The predictors of MTX treatment failure include the embryonic cardiac activity, the size and volume of the gestational mass $(>4 \mathrm{~cm})$, the presence of free peritoneal blood, the rapidly increasing $\beta$-hCG titers before methotrexate $(>50 \% / 48 \mathrm{~h})$, and the high initial $\beta$-hCG level $(>5,000 \mathrm{mUI} / \mathrm{ml})(55,61)$.

In conclusion, in this study, we investigated the early diagnosis and treatment of patients with ectopic pregnancy. Through joint detection of serum progesterone, $\beta$-hCG, and CA125 levels, as well as the changes in the proportion of immune cells, ectopic pregnancy could be diagnosed early. We then applied a MTX intervention in patients with ectopic pregnancy to terminate their embryonic development, and transvaginal ultrasound determination of gestational size demonstrated that MTX exhibited a viable clinical efficacy in patients with ectopic pregnancy. This article provides evidence for the early diagnosis of ectopic pregnancy and the selection of appropriate treatment methods, which may be of clinical significance for reducing the mortality of pregnant women and improving the future pregnancy rate of patients with ectopic pregnancy.

\section{Acknowledgements}

Not applicable.

\section{Funding}

No funding was received.

\section{Availability of data and materials}

The datasets used and/or analyzed during the current study are available from the corresponding author on reasonable request.

\section{Authors' contributions}

HL, YL, SW and HJ conducted the experiments. HL and YL analyzed the data. HL and YD wrote the paper, Y.D conceived the study.

\section{Ethics approval and consent to participate}

Written consents were obtained from all the participants. The Ethics Committee of The Second Hospital of Hebei Medical University approved all the experiments in this study.

\section{Patient consent for publication}

Not applicable.

\section{Competing interests}

The authors declare that they have no competing interests.

\section{References}

1. Alkatout I, Honemeyer U, Strauss A, Tinelli A, Malvasi A, Jonat W, Mettler L and Schollmeyer T: Clinical diagnosis and treatment of ectopic pregnancy. Obstet Gynecol Surv 68: 571-581, 2013.

2. Bronson R: Ectopic pregnancy-still a challenge. Fertil Steril 110: 1265-1266, 2018

3. Buster JE and Carson SA: Ectopic pregnancy: New advances in diagnosis and treatment. Curr Opin Obstet Gynecol 7: 168-176, 1995. 
4. Ma S, Xiang Y and Yang X: Diagnosis and treatment of ectopic molar pregnancy. Zhonghua Fu Chan Ke Za Zhi 36: 618-620, 2001 (In Chinese).

5. Taran FA, Kagan KO, Hubner M, Hoopmann M, Wallwiener D and Brucker $\mathrm{S}$ : The diagnosis and treatment of ectopic pregnancy. Dtsch Arztebl Int 112: 693-705, 2015.

6. Dai Z: Diagnosis and treatment of ectopic pregnancy should be strengthened. Zhonghua Yi Xue Za Zhi 77: 403-404, 1997 (In Chinese)

7. Murray H, Baakdah H, Bardell T and Tulandi T: Diagnosis and treatment of ectopic pregnancy. CMAJ 173: 905-912, 2005.

8. Epee-Bekima M and Overton C: Diagnosis and treatment of ectopic pregnancy. Practitioner 257: 15-17, 22, 2013.

9. Walid MS and Heaton RL: Diagnosis and laparoscopic treatment of cornual ectopic pregnancy. Ger Med Sci 8: pii: Doc16, 2010.

10. Jiang W, Lv S, Sun L, Singer G, Xu C and Lu X: Diagnosis and treatment of retroperitoneal ectopic pregnancy: Review of the literature. Gynecol Obstet Invest 77: 205-210, 2014.

11. Kirk E, Bottomley C and Bourne T: Diagnosing ectopic pregnancy and current concepts in the management of pregnancy of unknown location. Hum Reprod Update 20: 250-261, 2014.

12. Kaplan BC, Dart RG, Moskos M, Kuligowska E, Chun B, Adel Hamid M, Northern K, Schmidt J and Kharwadkar A: Ectopic pregnancy: Prospective study with improved diagnostic accuracy. Ann Emerg Med 28: 10-17, 1996.

13. Mol BW and Van der Veen F: A study of ruptured tubal ectopic pregnancy. Obstet Gynecol 90: 866-867, 1997.

14. Kohn MA, Kerr K, Malkevich D, O'Neil N, Kerr MJ and Kaplan BC: Beta-human chorionic gonadotropin levels and the likelihood of ectopic pregnancy in emergency department patients with abdominal pain or vaginal bleeding. Acad Emerg Med 10: 119-126, 2003.

15. Barnhart KT, Sammel MD, Rinaudo PF, Zhou L, Hummel AC and Guo W: Symptomatic patients with an early viable intrauterine pregnancy: HCG curves redefined. Obstet Gynecol 104: $50-55,2004$

16. Iwanari O, Miyako J, Date Y, Nakayama S, Kijima S, Moriyama M, Takahashi K, Yoshino N, Karino K, Endoh J, et al: Differential diagnosis of ovarian cancer, benign ovarian tumor and endometriosis by a combination assay of serum sialyl SSEA-1 antigen and CA125 levels. Gynecol Obstet Invest 29: 71-74, 1990.

17. Brumsted JR, Nakajima ST, Badger G, Riddick DH and Gibson M: Serum concentration of CA-125 during the first trimester of normal and abnormal pregnancies. J Reprod Med 35: 499-502, 1990.

18. Sadovsky Y, Pineda J and Collins JL: Serum CA-125 levels in women with ectopic and intrauterine pregnancies. J Reprod Med 36: 875-878, 1991.

19. Yao M and Tulandi T: Current status of surgical and nonsurgical management of ectopic pregnancy. Fertil Steril 67: 421-433, 1997.

20. Barnhart KT, Gosman G, Ashby R and Sammel M: The medical management of ectopic pregnancy: A meta-analysis comparing 'single dose' and 'multidose' regimens. Obstet Gynecol 101: 778-784, 2003.

21. Lipscomb GH, Bran D, McCord ML, Portera JC and Ling FW: Analysis of three hundred fifteen ectopic pregnancies treated with single-dose methotrexate. Am J Obstet Gynecol 178: $1354-1358,1998$

22. Fu $\mathrm{X}$, Meng $\mathrm{M}$, Zhang $\mathrm{Y}$, Yin $\mathrm{Y}$, Zhang $\mathrm{X}$ and $\mathrm{Xi} \mathrm{R}$ : Chemiluminescence enzyme immunoassay using magnetic nanoparticles for detection of neuron specific enolase in human serum. Anal Chim Acta 722: 114-118, 2012.

23. Feldman AT and Wolfe D: Tissue processing and hematoxylin and eosin staining. Methods Mol Biol 1180: 31-43, 2014.

24. Escobar-Padilla B, Perez-López CA and Martinez-Puon H: Risk factors and clinical features of ectopic pregnancy. Rev Med Inst Mex Seguro Soc 55: 278-285, 2017 (In Spanish).

25. Diagnosis and management of ectopic pregnancy: Green-top Guideline no. 21. BJOG 123: e15-e55, 2016

26. Alsunaidi M: Incidence of ectopic pregnancy after assisted reproduction treatment. Saudi Med J 28: 590-592, 2007.

27. Strandell A, Thorburn J and Hamberger L: Risk factors for ectopic pregnancy in assisted reproduction. Fertil Steril 71: 282-286, 1999

28. Bird S: Failure to diagnose: Ectopic pregnancy. Aust Fam Physician 34: 175-176, 2005.

29. Horne AW, Duncan WC and Critchley HO: The need for serum biomarker development for diagnosing and excluding tubal ectopic pregnancy. Acta Obstet Gynecol Scand 89: 299-301, 2010 .
30. Surampudi K and Gundabattula SR: The role of serum Beta hCG in early diagnosis and management strategy of ectopic pregnancy. J Clin Diagn Res 10: QC08-QC10, 2016.

31. Jacobson ED: Ectopic pregnancy and hCG. S Afr Med J 57: 887-888, 1980 (In Afrikaans).

32. Abdul-Hussein MM, Abdul-Rasheed OF and Al-Moayed HA: The values of CA-125, Progesterone, $\beta$-HCG and estradiol in the early prediction of ectopic pregnancy. Oman Med J 27: 124-128, 2012.

33. Alhamdan D, Bignardi T, Casikar I, Riemke J and Condous G: Pre-treatment human chorionic gonadotrophin (hCG) ratio in the management of non-tubal ectopic pregnancy. Ceylon Med J 56: 70-71, 2011

34. Ahlgren M, Friberg B and Sjöholm A: Diagnosis of suspected ectopic pregnancy using an immunoenzyme method for urinary HCG. Lakartidningen 84: 760-763, 1987 (In Swedish).

35. Buck RH, Pather N, Moodley J, Joubert SM and Norman RJ: Bedside application of an ultrasensitive urine test for HCG in patients with suspected ectopic pregnancy. Ann Clin Biochem 24: 268-272, 1987.

36. Cacciatore B, Stenman UH and Ylöstalo P: Diagnosis of ectopic pregnancy by vaginal ultrasonography in combination with a discriminatory serum hCG level of 1000 IU/l (IRP). Br J Obstet Gynaecol 97: 904-908, 1990

37. Nyberg DA, Filly RA, Laing FC, Mack LA and Zarutskie PW: Ectopic pregnancy: Diagnosis by sonography correlated with quantitative HCG levels. J Ultrasound Med 6: 145-150, 1987.

38. Bustillo M, Stern JJ, King D and Coulam CB: Serum progesterone and estradiol concentrations in the early diagnosis of ectopic pregnancy after in vitro fertilization-embryo transfer. Fertil Steril 59: 668-670, 1993.

39. Buck RH, Joubert SM and Norman RJ: Serum progesterone in the diagnosis of ectopic pregnancy: A valuable diagnostic test? Fertil Steril 50: 752-755, 1988.

40. Gelder MS, Boots LR and Younger JB: Use of a single random serum progesterone value as a diagnostic aid for ectopic pregnancy. Fertil Steril 55: 497-500, 1991.

41. Schmidt T, Rein DT, Foth D, Eibach HW, Kurbacher CM, Mallmann P and Römer T: Prognostic value of repeated serum CA 125 measurements in first trimester pregnancy. Eur J Obstet Gynecol Reprod Biol 97: 168-173, 2001.

42. Predanic M: Differentiating tubal abortion from viable ectopic pregnancy with serum CA-125 and beta-human chorionic gonadotropin determinations. Fertil Steril 73: 522-525, 2000.

43. Sauer MV, Vasilev SA, Campeau J and Vermesh M: Serum cancer antigen 125 in ectopic pregnancy. Gynecol Obstet Invest 27: 164-165, 1989.

44. Canney PA, Moore M, Wilkinson PM and James RD: Ovarian cancer antigen CA125: A prospective clinical assessment of its role as a tumour marker. Br J Cancer 50: 765-769, 1984

45. Jacobs IJ, Fay TN, Stabile I, Bridges JE, Oram DH and Grudzinskas JG: The distribution of CA 125 in the reproductive tract of pregnant and non-pregnant women. Br J Obstet Gynaecol 95: 1190-1194, 1988

46. Kobayashi F, Sagawa N, Nakamura K, Nonogaki M, Ban C, Fujii S and Mori T: Mechanism and clinical significance of elevated CA 125 levels in the sera of pregnant women. Am J Obstet Gynecol 160: 563-566, 1989.

47. Svirsky R, Ben-Ami I, Berkovitch M, Halperin R and Rozovski U: Outcomes of conception subsequent to methotrexate treatment for an unruptured ectopic pregnancy. Int J Gynaecol Obstet 139: 170-173, 2017.

48. Tas EE, Akcay GF and Avsar AF: Single-dose methotrexate for the treatment of ectopic pregnancy: Our experience from 2010 to 2015. Pak J Med Sci 33: 13-17, 2017.

49. Thoen LD and Creinin MD: Medical treatment of ectopic pregnancy with methotrexate. Fertil Steril 68: 727-730, 1997.

50. Tulandi T, Bret PM, Atri M and Senterman M: Treatment of ectopic pregnancy by transvaginal intratubal methotrexate administration. Obstet Gynecol 77: 627-630, 1991.

51. Usta IM, Nassar AH, Yunis KA and Abu-Musa AA: Methotrexate embryopathy after therapy for misdiagnosed ectopic pregnancy. Int J Gynaecol Obstet 99: 253-255, 2007.

52. van Mello NM, Mol F, Verhoeve HR, van Wely M, Adriaanse AH, Boss EA, Dijkman AB, Bayram N, Emanuel MH, Friederich J, et al: Methotrexate or expectant management in women with an ectopic pregnancy or pregnancy of unknown location and low serum hCG concentrations? A randomized comparison. Hum Reprod 28: 60-67, 2013. 
53. Weinman SA: Nonsurgical treatment of an ectopic pregnancy with methotrexate. J Emerg Nurs 22: 597-599, 1996.

54. Yang C, Cai J, Geng Y and Gao Y: Multiple-dose and double-dose versus single-dose administration of methotrexate for the treatment of ectopic pregnancy: A systematic review and meta-analysis. Reprod Biomed Online 34: 383-391, 2017.

55. Cecchino GN, Araujo Júnior E and Elito Júnior J: Methotrexate for ectopic pregnancy: When and how. Arch Gynecol Obstet 290: 417-423, 2014

56. Yao M, Tulandi T and Falcone T: Treatment of ectopic pregnancy by systemic methotrexate, transvaginal methotrexate, and operative laparoscopy. Int J Fertil Menopausal Stud 41: 470-475, 1996.

57. Ander DS and Ward KR: Medical management of ectopic pregnancy-the role of methotrexate. J Emerg Med 15: 177-182, 1997.
58. Atkinson M, Gupta S and McGee T: $\beta$ hCG monitoring after single-dose methotrexate treatment of tubal ectopic pregnancy: Is the Day $4 \beta$ hCG necessary? A retrospective cohort study. Aust N Z J Obstet Gynaecol 54: 475-479, 2014

59. Helmy S, Koch M, Kolbl H, Grohmann-Izay B, Solomayer E and Bader Y: Correlation of the volume of ectopic pregnancy and MTX therapy outcome: A retrospective cohort study. Eur J Obstet Gynecol Reprod Biol 184: 108-111, 2015.

60. Balasch J, Ballesca JL, Fábregues F, Puerto B, Casamitjana R and Vanrell JA: Transvaginal intratubal insemination, ectopic pregnancy and treatment by single-dose parenteral methotrexate. Hum Reprod 7: 1457-1460, 1992.

61. Sagiv R, Debby A, Feit H, Cohen-Sacher B, Keidar R and Golan A: The optimal cutoff serum level of human chorionic gonadotropin for efficacy of methotrexate treatment in women with extrauterine pregnancy. Int J Gynaecol Obstet 116: 101-104, 2012. 